\title{
SCLC extensive disease - treatment guidance by extent or/and biology of response?
}

\author{
Franziska Eckert and Arndt-Christian Müller*
}

\author{
Address: Department of Radiooncology, Eberhard-Karls-University Tübingen, Germany \\ Email: Franziska Eckert - franziska.eckert@med.uni-tuebingen.de; Arndt-Christian Müller* - arndt-christian.mueller@med.uni-tuebingen.de \\ * Corresponding author
}

Published: 2 October 2008

Radiation Oncology 2008, 3:33 doi:10.1/86/1748-7/7X-3-33

This article is available from: http://www.ro-journal.com/content/3/I/33

(c) 2008 Eckert and Müller; licensee BioMed Central Ltd.

This is an Open Access article distributed under the terms of the Creative Commons Attribution License (http://creativecommons.org/licenses/by/2.0), which permits unrestricted use, distribution, and reproduction in any medium, provided the original work is properly cited.
Received: I April 2008

Accepted: 2 October 2008

\begin{abstract}
In extensive disease of small cell lung cancer a doubling of the one-year-survival rate was reported in August 2007 by prophylactic cranial irradiation applied to patients who experienced any response to initial chemotherapy. We discuss the treatment concept of extensive disease in the face of the latest results and older studies with additional thoracic irradiation in this subgroup. A randomized trial with prophylactic cranial irradiation published in 1999 demonstrated an improvement of 5-year-overall-survival for complete responders (at least at distant levels) receiving additional thoracic radiochemotherapy compared to chemotherapy alone (9.1\% vs. $3.7 \%)$. But, these results were almost neglected and thoracic radiotherapy was not further investigated for good responders of extensive disease. However, in the light of current advances by prophylactic cranial irradiation these findings are noteworthy on all accounts. Considering both, a possible interpretation of these data could be a survival benefit of local control by simultaneous thoracic radiochemotherapy in the case of improved distant control due to chemotherapy and prophylactic cranial irradiation. Furthermore the question arises whether the tumor biology indicated by the response to chemotherapy should be integrated in the present classification.
\end{abstract}

\section{Background}

Extensive disease of small cell lung cancer (ED-SCLC) is still a therapeutical challenge. The median survival time without treatment reaches two to four months [1]. Standard therapy with four to six cycles of chemotherapy prolongs the median survival time to six to nine months. Even with the achievement of a complete response (CR), only a few months more are added to the short life expectancy.

The investigations of the last years mainly concentrated on more effective and less toxic drug regimens or on targeted therapies, but until now these attempts did not bear essential success. Astonishingly, a doubling of the one- year-survival rate was reported in August 2007 for a "conventional" technique: Prophylactic cranial irradiation (PCI) applied to patients who experienced any response to the initial chemotherapy [2].

\section{$\mathrm{PCl}$ and ED-SCLC}

For the first time an improved survival was shown for PCI by the mentioned EORTC-study in this favorable subgroup (at least partial response to chemotherapy). The bottom line was an increase of overall survival (27 vs. $13 \%$ one-year survival) based on improved local control with a highly significant reduction of symptomatic cerebral metastasis for patients treated with PCI (41 vs. 17\%). With the shortest of the applied radiation regimens this 
meant a gain in overall-survival of six weeks (5.4 vs. 6.7 months median survival) with a therapy of one week. The assessed quality of life was significantly better in the radiation group due to acceptable toxicities and reduced morbidity caused by cerebral metastasis. An additional advantage of PCI and related lower morbidity was the increased applicability of second-line chemotherapy. The study was designed with focus on easy feasibility and costeffectiveness. So, patients with symptomatic brain metastases were excluded and cross sectional imaging was not routinely demanded but performed in case of defined key symptoms. However, treatment of occult brain metastasis by PCI cannot be finally ruled out. Despite of this potential limitation, an older meta-analysis evaluating complete responders of SCLC illustrates the main principle that PCI improves survival (benefit of $5.4 \%$ at 3 years) [3]. Approximately $20 \%$ of complete responders included in this meta-analysis were staged as extensive disease. The subgroup-analysis revealed no significant difference between limited and extensive disease (relative risk of death for limited/extensive SCLC: 0.85 vs. $0.77 \mathrm{p}=0.88$ ).

Local recurrence plays an increasing role in ED-SCLC. After thoracic radiation treatment, in-field relapse occurred in $24 \%$ of the cases as the first site of relapse [4]. Without local treatment $89-93 \%$ patients suffered from local progress in the first year after primary therapy [2].

\section{Additional local radiotherapy for extensive disease?}

Already in 1999 a study performed by a Serbian group [5] evaluated different local treatment approaches depending on response to initial chemotherapy. Those who had complete response at least at distant levels were randomized to receive either two courses of cisplatin/etoposide (each $80 \mathrm{mg} / \mathrm{m}^{2}$ ) or TRT with daily carboplatin/ etoposide (each $50 \mathrm{mg} / \mathrm{m}^{2}$ ). Subsequently, PCI and two more courses chemotherapy were performed. Interestingly thoracic radiochemotherapy improved 5-year overall-survival compared to chemotherapy (9.1\% vs. 3.7\%).

Four older studies [6-9] investigating the value of TRT without standard PCI for extensive disease were unable to detect any benefit from treatment. However, besides absence of PCI, chemotherapy was applied sequentially and not concurrent with TRT. Furthermore, the limited case number of all four trials together (129 vs. 109 in the study of Jeremic et al.) suggests a lower statistical power of the negative studies. Staging deficits of the earlier investigations in the late eighties might also be assumed. A possible interpretation of these data on TRT could be a survival benefit of local control by simultaneous radiochemotherapy in the case of improved distant control due to chemotherapy and PCI. TRT has never been implemented into clinical treatment concepts for ED-SCLC. However, these findings are noteworthy on all accounts potentially improving the outcome of good responders with extensive disease.

\section{Conclusion}

Taken together the results of Slotman et al. and Jeremic et al. lead to the question whether the treatment for extensive disease SCLC should be reconsidered. There could be three different treatment strategies according to initial response to chemotherapy: Chemotherapy plus TRT (simultaneously with the $4^{\text {th }}$ cycle) and PCI for good responders achieving complete remission at least at distant levels; chemotherapy and PCI for patients having less than complete response; second line chemotherapy or best supportive care for stable or progressive disease (Figure 1). If this therapy was established, the difference in treatment of limited and extensive disease in complete responders would diminish. The best estimated 5-yearoverall-survival for the described schedule could exceed $20 \%$ for limited and reach almost $10 \%$ for extensive disease $[4,5,10]$. Based on the available data the question arises, whether the present classification should be supplemented by biology of response. Surely, randomized trials are essential to evaluate this proposed procedure. Furthermore, the significance of potential confounders like treatment of asymptomatic brain metastasis by PCI, prognostic relevance of metastatic pattern within the heterogeneous group of ED-SCLC and subsequent second line treatment could be analyzed.

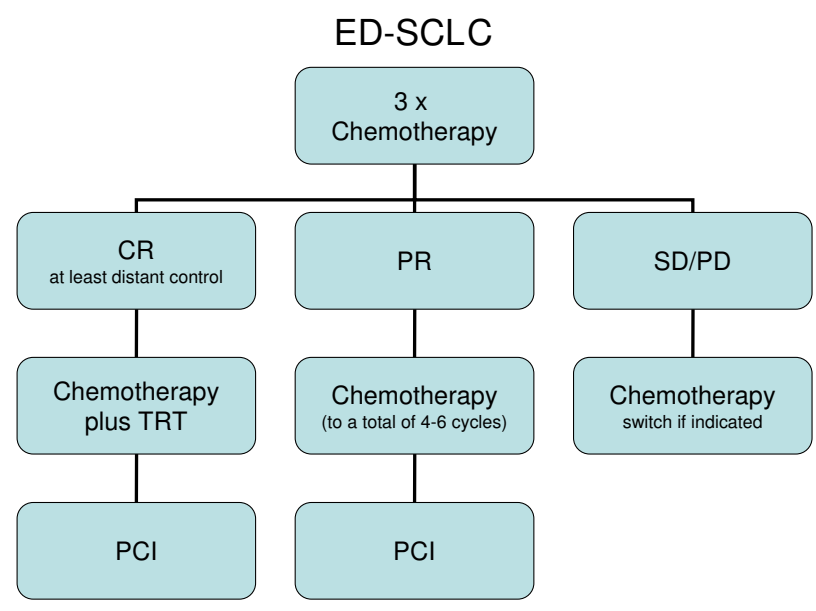

\section{Figure I}

Suggested treatment strategy for ED-SCLC. Based on recent and older, hardly considered data [2,5] there could be three different treatment strategies according to initial response to chemotherapy: Chemotherapy plus TRT (simultaneously with the $4^{\text {th }}$ cycle) and $\mathrm{PCl}$ for good responders achieving complete remission at least at distant levels; chemotherapy and $\mathrm{PCl}$ for patients having any response; second line chemotherapy or best supportive care for stable or progressive disease. 


\section{Competing interests}

The authors declare that they have no competing interests.

\section{Authors' contributions}

FE drafted the manuscript, drafted the figure. ACM conceived the manuscript. All authors read and approved the final manuscript.

\section{References}

I. Samson DJ, Seidenfeld J, Simon GR, Turrisi AT 3rd, Bonnell C, Ziegler $K M$, Aronson $N$ : Evidence for management of small cell lung cancer: ACCP evidence-based clinical practice guidelines (2nd edition). Chest 2007, 132:3|4S-323S.

2. Slotman B, Faivre-Finn C, Kramer G, Rankin E, Snee M, Hatton M, Postmus P, Collette L, Musat E, Senan S: Prophylactic cranial irradiation in extensive small-cell lung cancer. N Engl J Med 2007, 357:664-672.

3. Auperin A, Arriagada R, Pignon JP, Le Pechoux C, Gregor A, Stephens $\mathrm{RJ}$, Kristjansen PE, Johnson BE, Ueoka $\mathrm{H}$, Wagner H, Aisner J: Prophylactic cranial irradiation for patients with small-cell lung cancer in complete remission. Prophylactic Cranial Irradiation Overview Collaborative Group. N Engl J Med 1999, 34I:476-484.

4. Saito H, Takada Y, Ichinose Y, Eguchi K, Kudoh S, Matsui K, Nakagawa K, Takada M, Negoro S, Tamura K, et al.: Phase II study of etoposide and cisplatin with concurrent twice-daily thoracic radiotherapy followed by irinotecan and cisplatin in patients with limited-disease small-cell lung cancer: West Japan Thoracic Oncology Group 9902. J Clin Oncol 2006, 24:5247-5252.

5. Jeremic B, Shibamoto Y, Nikolic N, Milicic B, Milisavljevic S, Dagovic A, Aleksandrovic J, Radosavljevic-Asic G: Role of radiation therapy in the combined-modality treatment of patients with extensive disease small-cell lung cancer: A randomized study. J Clin Oncol 1999, 17:2092-2099.

6. Brincker H, Hindberg J, Hansen PV: Cyclic alternating polychemotherapy with or without upper and lower half-body irradiation in small cell anaplastic lung cancer. A randomized study. Eur J Cancer Clin Oncol 1987, 23:205-2II.

7. Lebeau B, Chastang C, Brechot JM, Capron F: A randomized trial of delayed thoracic radiotherapy in complete responder patients with small-cell lung cancer. Petites Cellules Group. Chest 1993, 104:726-733.

8. Nou $E$, Brodin $O$, Bergh J: A randomized study of radiation treatment in small cell bronchial carcinoma treated with two types of four-drug chemotherapy regimens. Cancer 1988, 62:1079-1090.

9. Rosenthal MA, Tattersall MHN, Fox RM, Woods RL, Brodie GN: Adjuvant thoracic radiotherapy in small cell lung cancer: ten-year follow-up of a randomized study. Lung Cancer 1991, 7:235-241.

10. Turrisi AT 3rd, Kim K, Blum R, Sause WT, Livingston RB, Komaki R Wagner $\mathrm{H}$, Aisner $\mathrm{S}$, Johnson $\mathrm{DH}$ : Twice-daily compared with once-daily thoracic radiotherapy in limited small-cell lung cancer treated concurrently with cisplatin and etoposide. $N$ Engl J Med 1999, 340:265-27I.
Publish with Biomed Central and every scientist can read your work free of charge

"BioMed Central will be the most significant development for disseminating the results of biomedical research in our lifetime. "

Sir Paul Nurse, Cancer Research UK

Your research papers will be:

- available free of charge to the entire biomedical community

- peer reviewed and published immediately upon acceptance

- cited in PubMed and archived on PubMed Central

- yours - you keep the copyright
BioMedcentral 